\title{
LA PÉRDIDA DE LAS TIERRAS DE LOS INDIOS DE COPIAPÓ (SIGLOS XVI-XIX): ECONOMÍA EXTRACTIVISTA COLONIAL HISPANA EN EL NORTE SEMIÁRIDO CHILENO*
}

\author{
THE LOSS OF THE COPIAPO INDIANS LANDS (XVI-XIX CENTURIES): \\ HISPANIC COLONIAL EXTRACTIVIST ECONOMY IN THE NORTH \\ SEMI-ARID OF CHILE
}

\author{
Enrique Cortés Larravide**
}

\begin{abstract}
Si bien la irrupción de los europeos en el continente americano supuso cambios drásticos a todo nivel en los grupos que ocupaban dichos territorios, la documentación temprana no permite siempre ver de manera cabal cómo fue este proceso a nivel local. Para el valle de Copiapó, situado en el extremo norte de la zona semiárida chilena, tenemos datos historiográficos que brindan información de relativa precisión que hace posible ordenar de forma cronológica las fases que llevaron a los grupos locales a perder gran parte de su territorio. Mediante el estudio de la historia regional es posible dar cuenta del peso que tuvieron los intereses económicos coloniales en dicho proceso.
\end{abstract}

Palabras claves: Copiapó, tierras indígenas, pueblo de indios, período colonial, economía colonial, extractivismo.

Although the emergence of Europeans on the American continent meant drastic changes at all levels in the groups that occupied these territories, early documentation does not always allow us to fully see what this process was like at the local level. For the Copiapó valley, located in the extreme north of the Chilean semi-arid zone, we have historiographic data that provides relatively accurate information that makes it possible to chronologically order the phases that led local groups to lose much of their territory. Through the study of regional history, it is possible to account for the weight that colonial economic interests had in this process.

Key words: Copiapó, indigenous lands, Indian pueblos, colonial period, colonial economy, extractivism.

\section{La irrupción europea en América: el dilema de la supervivencia comunitaria}

Cuando a las vísperas del período republicano chileno, a inicios del siglo XIX, se recogieron en los archivos testimonios directos por parte de miembros del pueblo de indios de Copiapó, también denominado San Fernando de Copiapó, se ignoraba por entonces que serían los últimos provenientes de un grupo autóctono que presentaba cierta cohesión social desde mediados del siglo $\mathrm{XVI}^{1}$, y con una continuidad cultural desde el período agroalfarero temprano. Tras el fin del período colonial, el grupo se esfumó como tal, quedando en la zona individuos portadores de esa historia, pero que dejaron de actuar como el ente social que hasta entonces era considerado como el indio de Copiapó ${ }^{2}$. Ya hacia 1813 menos de un cuarto de la población de este pueblo entraba en la categoría social de autóctono, siendo el resto españoles, mestizos o mulatos (Egaña 1953 [1813]). Las causas de esta desaparición progresiva son múltiples pero apuntan a una dirección: la importancia que tomó la explotación agropecuaria y minera desde inicio del período colonial en desmedro de la población autóctona del valle.

Lo ocurrido en Copiapó no fue una excepción. Por el contrario, factores causales similares suelen aparecer en documentos de la época como motores que llevaron a muchos grupos autóctonos a situaciones de suma vulnerabilidad. Los estudios realizados por investigadores han demostrado que en muchísimos casos la llegada de los europeos a América trajo consigo nuevos sistemas económicos que implicaron sacrificar la suerte de muchos grupos indígenas del continente. Para Chile, observamos el colapso

\footnotetext{
* Este artículo es el resultado de reflexiones emprendidas durante la redacción de la tesis doctoral y que fueron presentadas y debatidas durante la jornada de estudios "Grands espaces américains" organizada por el CREDA el 4 de diciembre de 2017 en el CNRS-Ivry sur Seine, Francia.

** Investigador asociado al Centro de Investigación y de Documentación de las Américas (CREDA UMR 7227) y al Centro de Investigación sobre la América Prehispánica (CeRAP EA 3551). Correo electrónico: enlicode2@ hotmail.com
} 
de los grupos que ocupaban los valles centrales (Bengoa 2015; Contreras Cruces 2016) o los de la Patagonia en tiempos modernos (Harambour R. 2015). Se ha señalado igualmente que apenas iniciada la Conquista de América, las sociedades autóctonas antillanas habrían sido sacrificadas en el altar agrominero (Córdova 1968; D’Esposito y Jacobs 2015; Valcárcel Rojas 2015). En el presente por ejemplo, en la Amazonía existen denuncias constantes por el avance de las explotaciones agrícolas y extractivas mineras (Nugkuag Ikanán 1994; Navia López 2019), algo que ya ocurría entre finales del siglo XIX y principios del XX con los productores de caucho (Steiner Sampedro et al. comp. 2014).

Sin embargo, tampoco fueron escasos los grupos que lograron hacer de la presencia europea una ventaja adaptándose por medio de múltiples restructuraciones y resignificaciones sociales, simbólicas y religiosas. Uno de los casos más emblemáticos es el de los comanches, quienes aprovechando las ambiciones y oposiciones de los estados occidentales en Norteamérica conjugado a enemistades entre grupos autóctonos llegaron a crear un verdadero imperio indígena (Hämäläinen 2012). En la región de Huaylas, los caciques lograron posicionarse como intermediarios entre las comunidades indígenas y el poder colonial, transformándose en vínculos eficaces y preservando así los intereses de los diferentes grupos encomendados y pueblos de indios frente a la administración colonial (Zuloaga Rada 2012). Para el caso de los grupos que ocupaban la región meridional del Chile central (los Reche), dos estudios marcaron un antes y un después respecto de la cuestión Mapuche, permitiendo hoy analizar la historia de ellos bajo un prisma nuevo, en el que el contacto, a pesar de la violencia que este trajo consigo, abrió paso a una sociedad expansionista (Boccara 1998; Zavala 2000). Existen también procesos que conllevaron a la invisibilización de grupos indígenas, sobre todo durante el período republicano, y que a la larga no han impedido la reemergencia de dichas entidades, reconocidas estatalmente como etnias, como ocurrió en el 2006 con la diaguita y en octubre de 2020 con la chango ${ }^{3}$.

Ahora bien, cuando grupos que ocupan un ecosistema de suma fragilidad, como lo es el valle de Copiapó, y que se ven enfrentados a situaciones de dominación en contexto de contacto, el margen que dichas poblaciones tienen para encontrar medios básicos de supervivencia es limitado (Garrido y
González 2020). Es indudable que la resistencia militar al colonizador fue una opción estratégica empleada a lo largo del continente; en Copiapó esta duró hasta $1554^{4}$ (Ruiz Rodríguez 2005). Sin embargo, esta alternativa no resultó satisfactoria. La emigración del grupo fue quizá considerada en algún momento por los indígenas pero debió haber sido descartada, porque el valle estaba situado en una encrucijada geográfica, en un oasis en medio del desierto ${ }^{5}$. Es aquí donde surgió, como una alternativa certera, la negociación (Garrido y González 2020).

\section{Las tierras de los indios del valle y la conquista española: la consolidación del poder de la tierra en manos del linaje Aguirre}

Los estudios arqueológicos han puesto énfasis en que los grupos humanos del valle de Copiapó tuvieron una continuidad cultural desde al menos la irrupción del período temprano, asociado al horizonte cultural Molle (Niemeyer 1998) que les permitió no solo ocupar progresivamente diferentes espacios en el valle, perfeccionando tecnologías agrícolas y mineras a la par que integraban influencias provenientes de otras regiones como del NOA o Atacama, e impulsando cambios en el seno mismo de su territorio (Castillo Gómez 1998; Garrido 1997; González Godoy 2018) ${ }^{6}$. Hasta 1551 los indios del valle gozaban aún del uso de todas las tierras del valle y de sus alrededores, ocupando diversos ecosistemas que se extendían desde la zona cordillerana hasta alcanzar el borde marítimo, así como ciertas tierras fuera del valle, en Marquesa (valle de Elqui).

El contacto hispano-indígena, que comenzó en marzo de 1536 con la entrada de las huestes del Adelantado Diego de Almagro por las cabeceras del valle de Copiapó, y la consiguiente colonización de la región, supuso para los habitantes de dicho territorio cambios drásticos que provocaron un colapso global de los grupos que ocupaban el valle. En 1558 el licenciado Santillán, encargado de visitar y reglamentar el trabajo de los indios encomendados de todo el reino de Chile, dejaba constancia que "los indios [de Copiapó] son mas capaces que ninguno de las dychas provincias" (Santillán 2004:184 [1558]), testimonio de suma paradoja cuando observamos la situación de esta misma encomienda a finales del siglo XVI: entre 1536 y 1595 hubo un descenso demográfico que se 


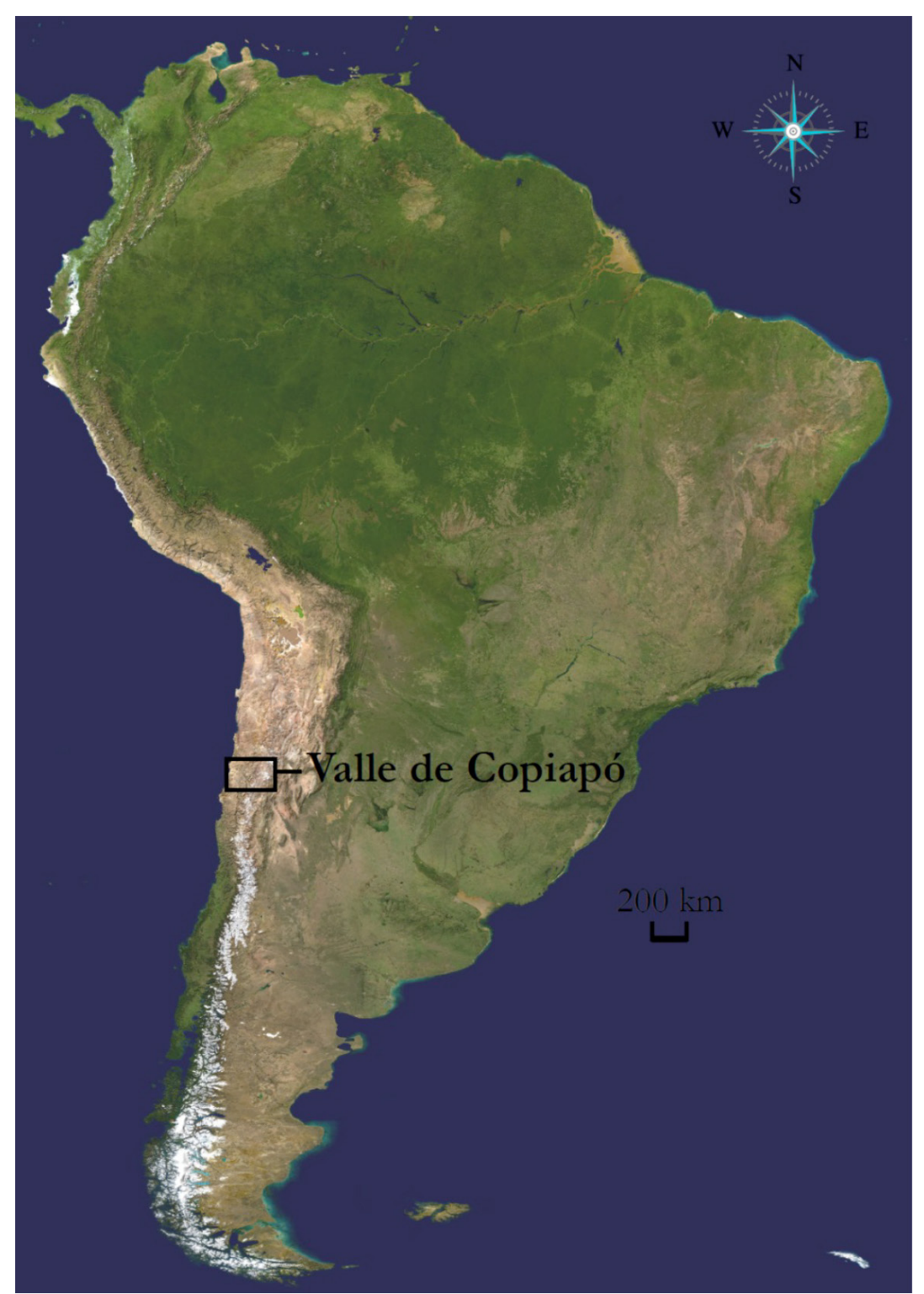

Mapa 1. América del Sur y el valle de Copiapó.

estima entre 90\% (Hidalgo Lehuedé 2004 [1971]) y 95\% (Cortés Larravide 2014).

Según los testimonios coloniales, a mediados del siglo XVII los diferentes grupos parecen haber sido desmembrados y desposeídos de sus tierras, perdurando solo tres grupos independientes entre ellos pero unidos al mismo encomendero. El primero de ellos, que es al que se refiere este artículo, era el grupo que residía en el valle de Copiapó y que se limitaba a ocupar unas parcelas cercanas al pueblo de indios del valle. El segundo era el de Marquesa, que tenía su propio cacique y que no parece mantener relación directa con los de Copiapó, más allá de aquella impuesta por el encomendero. Por último, los grupos de pescadores estaban ahora alejados de la zona costera aledaña al valle, viviendo y realizando sus actividades económicas en los territorios de Atacama y Charcas (Bittmann 1984:328).

Toda esta situación estaba ligada a diferentes procesos concomitantes que tuvieron lugar a lo largo de los siglos XVI y XVII: pérdida de las tierras comunitarias, descenso demográfico, reorientaciones 
económicas coloniales, desplazamiento forzoso de los indios hacia las zonas productivas, decadencia del señorío étnico como entidad unificadora y centralizadora de la comunidad y, por fin, catástrofes naturales ${ }^{7}$. Dichos procesos tuvieron lugar en un tiempo extremadamente acotado, siendo la gran catalizadora de todo ello la conquista de la región por el capitán Francisco de Aguirre, ya que provocó la desarticulación definitiva de la resistencia local al europeo.

Apenas iniciada la conquista de Chile, los españoles intentaron establecer un perímetro urbano en el valle de Copiapó para así controlar las actividades económicas locales y el tránsito entre la Capitanía General de Chile y Charcas y Perú. Fue así como hacia 1548 el capitán español Juan Bohón ordenó la construcción de un fuerte, no lejos de lo que parece haber sido un puesto importante para la administración inka en el valle conocido como La Puerta (Castillo Gómez 1998). Esto sugiere que quizá Bohón quiso legitimar la presencia española en Copiapó mediante este acto simbólico, como parece igualmente haber ocurrido en el valle de Elqui con la primera fundación de la ciudad de $\mathrm{La}$ Serena, no lejos de la sede inka regional (Lovera 1865 [1595]). El Fuerte, nombre con el que se le conoce a este primer establecimiento hispano en el valle, no resistió el levantamiento indígena de 1548 que tuvo lugar en todo el Norte Chico, y durante este alzamiento la ciudad de La Serena fue igualmente destruida. Ignoramos qué papel jugó en tan corto período de existencia. Las fuentes no precisan si el capitán Bohón logró organizar la mano de obra local pero sospechamos que tal objetivo no fue alcanzado, porque la población local no fue pacificada. Además, a pesar de que El Fuerte fue establecido con un claro propósito de planificación urbana (Cortés Lutz 2011), no llegó a ser más que un centro de comando militar que nunca alcanzó su propósito inicial.

Copiapó recién verá nacer un establecimiento protourbano tras las campañas de pacificación emprendidas por el capitán Francisco de Aguirre, quien logró consolidar de forma definitiva la presencia hispana en la región. Los diferentes grupos indígenas presentes en el valle se vieron profundamente afectados por dicha pacificación, ya que el proceso de colonización emprendido por Aguirre fue muy diferente al que Bohón llevó a cabo. En efecto, en 1548 este último se estableció junto con un grupo de 40 soldados en un espacio asociado al ocupante inka, mientras que Aguirre ordenó la erección de una casa que se volvería el centro neurálgico de sus asuntos económicos locales así como uno de sus tantos hogares de reposo para él y los suyos en un sitio densamente poblado por indígenas de Copiapó ${ }^{8}$, ocupando entonces un espacio asociado al mundo local. El pacificador del Norte Chico plantó viñas y árboles frutales (Sayago 1997 [1874]). A pesar de que no hayamos encontrado testimonios de la manera cómo organizó este nuevo espacio político y económico ni tampoco de cómo accedió a estos terrenos, es probable, tal como lo indicaron Borde y Góngora acerca de los encomenderos (1956:29), que Aguirre debió haber accedido a las mejores tierras dentro del pueblo de los indios encomendados. Se ha sugerido igualmente que una compañía religiosa estableció una sede local (Iturriaga 2006), lo que estaría indicando que Aguirre habría iniciado por medio de ello la creación del pueblo español de Copiapó.

Todos estos elementos esenciales al nuevo orden hispano (administrativo, militar, económico, político y religioso) fueron establecidos en las cercanías de jefes étnicos importantes del valle, según vemos en diversos fondos de archivos coloniales. Desde allí se emprendió, en definitiva, la colonización de los diferentes espacios del valle en desmedro de los grupos locales, quienes perdieron primero su autonomía política, y luego territorial y económica. Ignoramos cuáles fueron las primeras tierras que los nuevos sujetos encomendados perdieron con la llegada de los españoles, entre el período que culmina con la pacificación, en 1551, y la primera visita al valle, en 1558. ¿Fueron terrenos que algún grupo relacionado directamente con el Tawantinsuyo haya ocupado en el valle? La presencia inka trastocó profundamente la organización del espacio y de los grupos locales en la región previamente a la llegada de los españoles (Cortés Larravide 2016); la arqueología nos sugiere que los del Cuzco se sustentaron en sus aliados del valle de Elqui (los diaguitas chilenos) para avanzar hacia el valle de Copiapó e instalarse allí (Castillo Gómez 1998). Mas ignoramos el devenir de estos mitmakuna diaguitas chilenos o funcionarios del Tawantinsuyo tras el período de contacto. Es más, incluso quedan aún muchos vacíos en torno a las continuidades y rupturas étnicas, religiosas, políticas, económicas y sociales experimentadas en el valle durante el proceso histórico que se extiende entre las primeras entradas inkas en la región y la consolidación hispana en la zona (Cortés Larravide 2016, 2021). 
A partir de finales de 1561 los indios del valle manifestaron ante las autoridades españolas su voluntad de vender tierras al mejor postor a cambio de ganado, dándose así inicio a la primera transacción legal entre españoles e indios de Copiapó (ANCh, RA, vol. 1335, No 16; ANCh, Capitanía General [CA], vol. 578, s/ $\mathrm{N}^{\circ}$ ). Este acto, concretado en febrero de 1562, supuso la compra por parte de Diego de Villarroel, sobrino del conquistador Aguirre e igualmente compañero de armas, de un terreno yuxtapuesto al de este último y al de algunas autoridades étnicas locales, al suroeste del pueblo de Copiapó. Tras un rápido juego de cesiones de propiedades fue finalmente Aguirre quien tomó la posesión de un importante espacio productivo que le permitió construir un pequeño ingenio azucarero (Sayago 1997 [1874]). Si bien podemos considerar que esta primera venta le permitió a ciertos grupos locales reconstruirse desde un punto de vista económico a la par que aprendían nuevas prácticas económicas, fueron los españoles quienes lograron sacar mayor provecho de esta compraventa en un contexto en donde no se implementaban aún políticas en torno a las reducciones, es decir, de normas que impedían a los españoles instalarse en terrenos pertenecientes a grupos locales.

Paralelamente a estas ventas comenzó otro proceso: la adjudicación de mercedes de tierra. Mientras que con las ventas de tierras indígenas solo vemos cesiones de pequeños espacios productivos, debido a que los españoles mostraban su interés por instalarse en cercanías de un núcleo urbano, este segundo proceso se implementó en espacios más extensos, supuestamente abandonados por grupos locales, de quienes ya no se tenía noticia alguna. Estas mercedes comenzaron tímidamente en el siglo XVI, prosiguiendo su cauce a lo largo de todo el período colonial. La primera y única merced de tierra concedida en el primer siglo de ocupación hispana fue aquella otorgada al conquistador Aguirre por el gobernador del Reino de Chile, don Rodrigo de Quiroga, en 1576 (ANCh, RA, vol. 2498, $N^{\circ} 19$ ). Fue un vasto espacio que se desplegaba desde los límites del cacique don Francisco Guanitay, hacia el oeste de la ciudad de Copiapó, hasta el mar. Estas tierras se les nombraban Mole en un comienzo, siendo luego denominadas como La Ramadilla. ¿Se trató de un espacio que perteneció antes de 1576 a un grupo desaparecido, o de una expropiación "legal" de tierras autóctonas?
Veremos en el acápite siguiente cómo Francisco de Aguirre, mediante diferentes medios implementados por él mismo gracias a sus hazañas militares, pudo constituir para él y su descendencia, en un cuarto de siglo, entre 1551 y 1576 , un vasto espacio rural entre el pueblo de Copiapó y el océano Pacífico. Se transformó en el beneficiario exclusivo de toda la mano de obra autóctona del valle en 1549 (Valdivia 1898:221-222 [1549]). Paralelamente logra pacificar gran parte de la gobernación de Tucumán, transformándose así en su gobernador. Por otro lado, durante todo este período fue beneficiado con otras concesiones de tierras en el Norte Chico: las estancias y haciendas de Marquesa la Alta y Marquesa la Baja, en el valle de Elqui, la estancia de Tongoy, en la costa cercana al valle de Limarí, y las haciendas de Limarí y de Tamaya, igualmente en el valle de Limarí (Cortés Olivares 2003:40). No solo llegó a ser dueño de un inmenso territorio sino que además logró traspasarlo a su descendencia junto con una mano de obra encomendada, la de los indios del valle de Copiapó.

\section{La pérdida de la tierra: 1544-1657}

A finales del siglo XVII los indios encomendados del valle ocupaban un territorio bastante reducido. El grupo había perdido, a causa del alud de 1655, su única fuente de ingresos importante, el último acceso que poseían a un espacio productivo comunitario en el valle, ya que con anterioridad la gran mayoría de los terrenos fértiles habían sido distribuidos, por medio de diferentes estrategias, a los españoles. Las primeras concesiones de tierras que favorecieron a estos tuvieron probablemente lugar de forma simultánea a la de la encomienda. Ambos procesos se gestaban a la par. Aguirre instaló un solar en medio de terrenos autóctonos, quienes estaban encomendados en él mismo, y antes de él, Bohón había sido beneficiado con una encomienda en 1544, lo que le habría permitido seguramente obtener una merced de tierras (Cortés Lutz 2011).

Tal como indicamos en el acápite anterior, hacia 1561 las autoridades étnicas del valle, doña Ana y doña Catalina (Cortés Larravide 2014), emprendieron negociaciones con las autoridades hispanas con el objetivo de intercambiar parte de terrenos colectivos por ganado. Esta extensión de tierras lindaba con el pueblo de indios de Copiapó (ANCh, RA, vol.2498, $\mathrm{N}^{\circ}$ 19). Dicho expediente indica que años más tarde, en 1576, doña María, hija 
de doña Ana, inició un nuevo proceso de intercambio de tierras con los españoles. Esta vez se trató de terrenos situados al oeste de aquellos traspasados en 1561, en dirección del mar. Fueron en total una porción de 10 cuadras de largo por 6 de ancho. Un año más tarde, el gobernador del reino, don Rodrigo de Quiroga, otorgó una merced de tierras a su antiguo compañero, el capitán Aguirre, desde las tierras de Chamonate donde los indios tenían sus sembrados y un pueblo, hasta el océano, incluyendo el puerto de pesca. Aguirre transfirió dicha merced a su hijo Marco Antonio de Aguirre tres años más tarde (ANCh, RA, vol. 2498, No 19).

Este proceso se aceleró durante el siglo XVII, porque ya a inicios de la nueva centuria, en 1606, el gobernador del reino don Alonso García Ramón favoreció con una merced de tierras al capitán don Francisco de Riberos Figueroa ${ }^{9}$. Dicha merced estaba dividida en dos propiedades: la estancia de Mole y la estancia de Camasquil (ANCh, RA, vol. 2498, No 19; Sayago 1997:103 [1874]; Cortés Olivares 2005). En 1621 y en 1657 todos los terrenos productivos restantes en el valle fueron otorgados como mercedes de tierras a españoles descendientes o emparentados con la estirpe Aguirre, como se puede ver en la Tabla 1.

Fue así como, mientras las primeras concesiones de tierras fueron impulsadas sobre todo por los indios de Copiapó, ya a finales del siglo XVI este proceso parece ser similar al de esta encomienda: el monopolio exclusivo de la mano de obra local y la tierra disponible por parte del linaje Aguirre.

Las inundaciones de 1655 provocaron sin lugar a dudas una grave crisis en la sociedad encomendada del valle. Antes de esta catástrofe los indios respondían a sus obligaciones (tributo) y necesidades (vestimenta) vendiendo brea vegetal (Tessaria absinthioides), extraída en las últimas tierras a las que tenían acceso, en Nantoco ${ }^{10}$. Además, estos terrenos les permitían a los arrieros, a cambio de dinero, el acceso a una amplia zona de pastoreo antes de emprender largos viajes hacia Perú, donde transportaban cuero y sebo.

Los documentos coloniales indican que tras el alud que afectó las tierras de Nantoco, los indios de Copiapó comenzaron a utilizar la zona de Potrero Grande para extraer brea, hacia 1663. Para dicho período, el cacique del pueblo era don Francisco Taquía, quien por esos años había abandonado su pueblo (ANCh, RA, vol. 1763, $\mathrm{N}^{\circ}$ 1). Los indios no emprendieron ningún trámite legal para explotar esta tierra. El dueño de estas, don Juan de Cisternas, oponiéndose a esta iniciativa, les impidió el acceso a ellas, con lo que el protector de indios inició un recurso judicial que conllevó en primera instancia a la expulsión de Cisternas de esta hacienda, hacia 1668-1669. Sin embargo, este último presentó los títulos de merced de 1632 (merced de tierras de Juan Roco Campofrío) y una gran cantidad de testigos. Pudo así recuperar su propiedad en 1679 (ANCh, Notarial Copiapó [NC], vol. 1; ANCh, RA, vol. $\left.50, \mathrm{~s} / \mathrm{N}^{\circ}\right)$. Este fue el último evento relativo a la propiedad de la tierra que involucró a los indios de Copiapó. A partir de finales del siglo XVII los documentos coloniales solo recogerán datos de índole administrativa relacionada con estos últimos. Sin embargo, la presión de la economía colonial no dejó de acentuarse a lo largo del siglo siguiente.

\section{El aumento demográfico de la población española del valle: la agrominería como eje económico y elemento crucial en la desestructuración de la sociedad indígena}

La población española comenzó a volverse numerosa en las décadas que antecedieron a la creación de San Francisco de la Selva en 1744, en especial por la cantidad de minas que fueron descubiertas en la zona (ANCh, Fondos Varios [FV], vol. 342; Frézier 1995:155 [1717]; Carmagnani 1963; Torres Sánchez 1985); esto conllevó a que el pueblo de Copiapó fuese declarado ciudad (ANCh, FV, vol. 690). El gobernador Manso de Velasco se centró en la búsqueda e identificación de los recursos hídricos necesarios para la viabilidad del proyecto (ANCh, FV, vol. 690). En efecto, el plan de urbanismo preveía la construcción de una ciudad que agrupara al conjunto de la población española dispersada entre la costa y la cordillera. En cuanto a los indios de Copiapó, estaban agrupados en un pueblo colindante a la nueva ciudad: el Pueblo de Indios de San Fernando de Copiapó. Manso de Velasco, al darse cuenta que los recursos hídricos eran limitados, intentó desviar un afluente del río Copiapó (el río Turbio) para contrarrestar esta situación. Para ello ordenó que se averiguara esta posibilidad pero no halló en el valle nadie quien pudiese abocarse a la cuestión, ya que la población del valle consideró más oportuno continuar con las faenas agrícolas (ANCh, FV, vol. 690). A pesar de ello, San Francisco de la Selva fue levantada, lo que implicó la destrucción un gran número de 


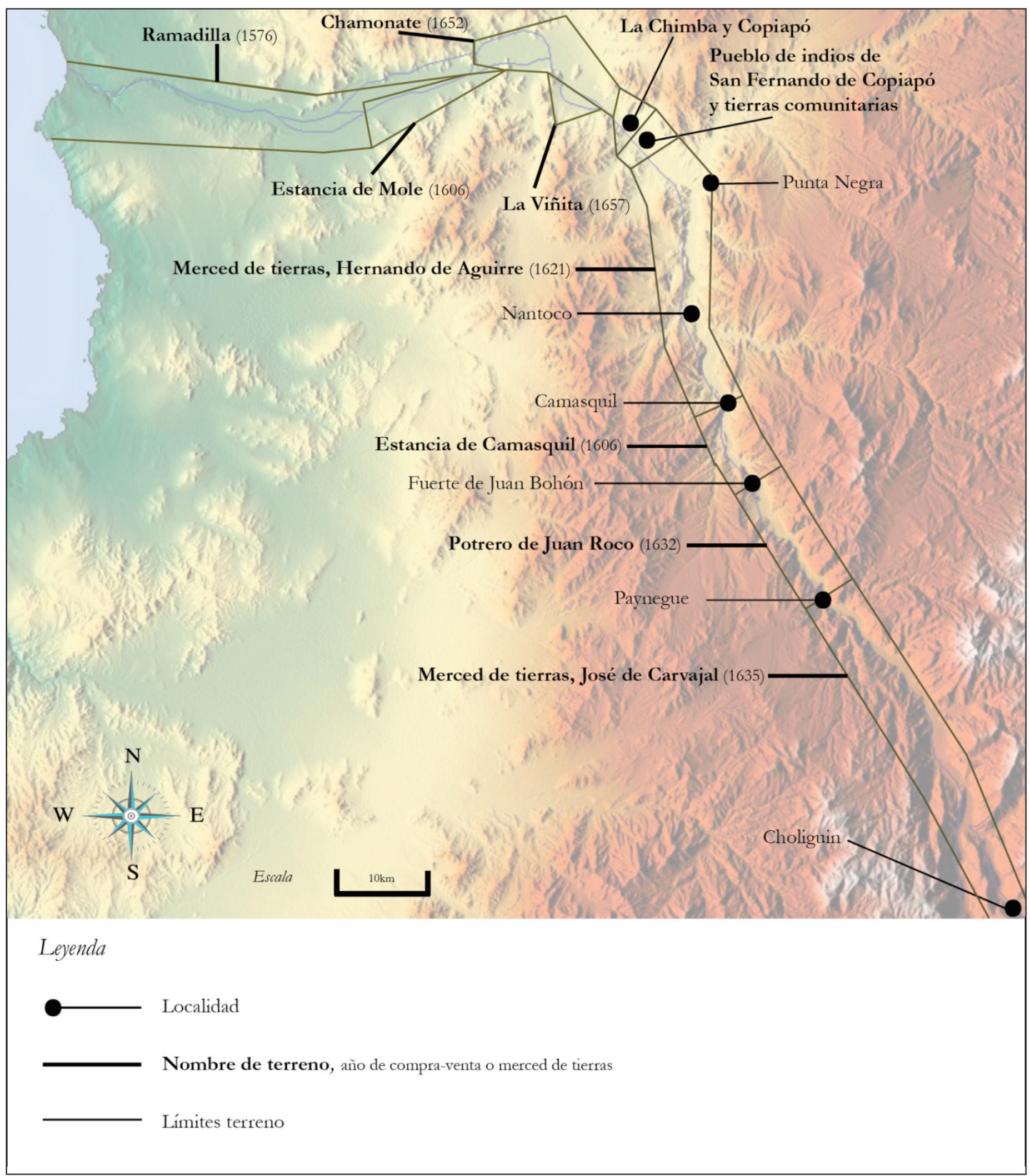

Mapa 2. El retroceso de las tierras autóctonas en el valle de Copiapó, 1561-1657.

árboles que fueron utilizados en la construcción de los edificios públicos y privados. En efecto, en 1755 el corregidor de Copiapó don Antonio Martín Apeolaza escribía al gobernador de Chile subrayando el hecho de que ya no había árboles en el valle, debido a ello varios proyectos de edificación habían sido suspendidos o frenados a causa de la tala descontrolada (Apeolaza 1995 [1756]). Mas en 1744 las autoridades habían indicado gran abundancia de árboles a lo largo del río (ANCh, FV, vol. 690). A mediano plazo, este proceso depredador tuvo sin lugar a dudas un papel primordial en el proceso de erosión en el valle, de desertificación regional, y del potencial hídrico del río (Granados-Sánchez et al. 2013), ya que esta vegetación retenía parte de las aguas en el suelo, frenando la velocidad de escurrimiento y reteniendo igualmente parte de la humedad ambiental. 
Tabla 1. El retroceso de las tierras autóctonas en el valle de Copiapó, 1544-1657.

\begin{tabular}{|c|c|c|c|}
\hline Año & Nombre/Localización & Beneficiario & Extensión \\
\hline $1544-1548$ & $\begin{array}{l}\text { Fuerte de Bohón (cercana a La } \\
\text { Puerta y Potrero Grande) }\end{array}$ & Juan Bohón (merced de tierras?) & ? \\
\hline 1548 & Casa solariega (Copiapó) & Francisco de Aguirre (merced de tierras?) ${ }^{\mathrm{b}}$ & $?$ \\
\hline 1561 & La Chimba y Copiapó & $\begin{array}{l}\text { Diego de Villarroel, quien la trapazó a María de Aguirre } \\
\text { Matienzo, esposa de Francisco de Aguirre (compra de } \\
\text { tierras) }^{c}\end{array}$ & $?$ \\
\hline 1575 & $\begin{array}{l}\text { "Lindan con las tierras de Francisco } \\
\text { de Aguirre, con el camino real que } \\
\text { viene del valle, con el tambo del } \\
\text { valle" }\end{array}$ & $\begin{array}{l}\text { Marco Antonio de Aguirre, hijo de Francisco de Aguirre } \\
\text { (compra de tierras) }^{\mathrm{d}}\end{array}$ & 60 cuadras \\
\hline 1576 & $\begin{array}{l}\text { La Ramadilla: "Desde las } \\
\text { sementeras de los indios y del } \\
\text { pueblo de Maria Che hasta el Puerto } \\
\text { de la Mar con el mismo Puerto" }\end{array}$ & $\begin{array}{l}\text { Francisco de Aguirre, quien las transfiere a su hijo } 3 \text { años } \\
\text { más tarde (merced de tierras) }\end{array}$ & $\begin{array}{l}1 \text { legua de } \\
\text { ancho }\end{array}$ \\
\hline 1606 & Estancia de Mole & Francisco de Riberos Figueroa (merced de tierras) ${ }^{\mathrm{d}, \mathrm{e}}$ & 500 cuadras \\
\hline 1606 & Estancia de Camasquil & Francisco de Riberos Figueroa (merced de tierras)e & 500 cuadras \\
\hline 1621 & Desde Punta Negra hasta Camasquil & $\begin{array}{l}\text { Hernando de Aguirre Matienzo, hijo de Francisco de } \\
\text { Aguirre (merced de tierras) }{ }^{b}\end{array}$ & 1.000 cuadras \\
\hline 1632 & $\begin{array}{l}\text { Potrero de Juan Roco (desde } \\
\text { el fuerte de Juan Bohón hasta } \\
\text { Paynegue) }\end{array}$ & $\begin{array}{l}\text { Juan Roco Carvajal (Juan Roco Campofrío) (merced de } \\
\text { tierras) } \text { f g }^{\text {g }}\end{array}$ & 1.000 cuadras \\
\hline 1635 & Desde Paynegue hasta Choliguín & $\begin{array}{l}\text { José de Carvajal, padre de Juan Roco Caravajal (merced } \\
\text { de tierras) }\end{array}$ & 1.000 cuadras \\
\hline 1652 & Chamonate & Juan de Cisternas Carrillo Escobar (merced de tierras) ${ }^{\mathrm{b}}$ & 4.000 cuadras \\
\hline 1657 & La Viñita & & \\
\hline
\end{tabular}

Fuentes: a) Cortés Lutz 2011; b) Sayago 1997 [1874]; c) ANCh, CG, vol. 578, s/Nº; d) ANCh, RA, vol. 2498, No 19; e) ANCh,

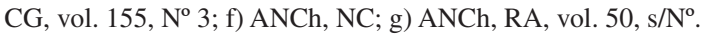

A su llegada, la principal actividad a la que se dedicaron los españoles en todo el Norte Chico fue la explotación minera, en particular la aurífera (Jara 1961; Salazar 2003). Con la disminución demográfica de la población local primero, y tras las reorientaciones económicas puestas en marcha en respuesta a los grandes mercados emergentes del centro andino después (Lima y por sobre todo Potosí), la producción minera se volvió minoritaria y la agricultura, por esta razón, en el centro de los intereses productivos regionales (Torres Sánchez 1985; Pinto Rodríguez 1988; Salazar 2003). En efecto, la economía del valle comenzó entonces a basarse en la exportación de bienes hacia el virreinato del Perú: combustibles de origen vegetal (brea) o animal (sebo), y productos alimenticios (trigo, pescado seco, frutos secos, vino, aguardiente). El valle poseía importantes zonas de pastizales, no tanto por su extensión sino por su situación estratégica (el borde del desierto), en las tierras altas de los contrafuertes andinos. Ellas les permitían a los arrieros emprender preparados el largo viaje entre Copiapó y Potosí (Sayago 1995 [1874]). Los productores agrícolas por su lado poseían terrenos valle arriba que permitían actividades agrícolas importantes. Los propietarios de estos terrenos, poco dispuestos a compartir las aguas del río, decidieron de manera unilateral, durante el siglo XVIII, utilizar de forma exclusiva las aguas del río y solo dejarlo pasar una vez regados todos sus sembrados. Esta situación generó diversos conflictos, algunos tramitados en tribunales, otros 
en instancias administrativas y autoridades de gobierno, sin solución alguna, al menos durante el siglo en cuestión. Estas disputas así como la gestión del río antes de estas fueron ampliamente documentadas en dicha época, lo que ha permitido que se realicen estudios profundos acerca del tema, en general en torno a las consecuencias que tuvo la explotación hídrica del río Copiapó en la formación de la sociedad colonial y republicana (Torres Sánchez 1985; Broll Carlin 1988; Berríos Drolett y Lucero Villavicencio 2011; Simón Ruiz y Sánchez Andaur 2018; Astudillo Pizarro 2018), al igual que las secuelas que dicho proceso dejó en los indios del valle (Cortés Larravide 2015). Todos apuntan a problemas sociales, políticos y ecológicos ocasionados por la superposición de los intereses productivos agromineros por sobre el resto de los intereses colectivos de la sociedad local, ya sea hispana como también indígena.

\section{Cuestiones inconclusas y reflexiones finales}

Los indios de Copiapó fueron víctimas, entre la llegada de los europeos y el inicio del período republicano, de un despojo sistemático de sus tierras. A pesar de que desplegaron diferentes estrategias a lo largo del período colonial, ya fuesen estas de índole militar (hasta 1554), de acercamiento y negociación (desde las primeras entradas de Almagro hasta el siglo XVIII), de carácter jurídico (durante los siglos XVII y XVIII) e incluso de levantamiento popular (a finales del siglo XVIII), en general cada una de ellas se revelaron insuficientes para contener el peso que supuso el extractivismo agrominero en desmedro de los intereses del grupo encomendado del valle. Llama la atención que situaciones similares continúan acechando la humanidad sin que haya un cambio de paradigma en torno a la relación que hay entre los diferentes grupos humanos, sea cual sea su posición social, su visión particular del entorno que las rodea, de su postura como seres humanos en un mundo hoy globalizado.
Además, queda aún mucho por investigar en torno a la cuestión indígena del valle de Copiapó. En efecto, ignoramos el devenir de este grupo en tiempos republicanos. ¿Abandonaron sus hogares y sus últimos resquicios de tierra como así lo indicaba su cacique a finales del siglo XVIII o bien permanecieron en el pueblo de San Fernando de Copiapó mezclándose con la incipiente población forastera que se instalaba en el pueblo, manteniendo así cierta continuidad cultural hasta hoy? Asimismo, debemos adentrarnos más en las dinámicas políticas y sociales vividas por el grupo a medida que se acrecentaba en la encomienda el porcentaje de indios provenientes de otras regiones, en particular aquellos de lengua mapuzungun. Se deberán emprender mayores investigaciones en torno al devenir de cada poblado presente en el momento del contacto, porque gran número de ellos desapareció con rapidez durante el período colonial. En relación con el pueblo de indios de San Fernando de Copiapó, conviene precisar que a pesar de que aún para el período republicano a veces se menciona a este grupo, como por ejemplo durante el censo general realizado en 1813 por Egaña (1953 [1813]), los procesos históricos que desencadenaron su colapso social solo son posibles comprenderlos en el marco de un proceso de largo plazo que comenzó con las primeras entradas españolas en los Andes Meridionales e incluso desde antes, con las primeras entradas inkas y diaguitas chilenas. No cabe duda que en lo referente al valle de Copiapó se necesitarán esfuerzos pluridisciplinares que permitan no solo desenmarañar documentos que aún no hayan sido analizados bajo el prisma del investigador sino que también estudiar yacimientos arqueológicos, prehispánicos como también coloniales y republicanos, realizar trabajos de terreno que recojan testimonios acerca del pasado regional, estudiar la lengua local, comprender con mayor precisión las dinámicas étnicas prehispánicas. Queda aún mucho por recorrer en el estudio de los grupos autóctonos del valle de Copiapó y en su devenir, sobre todo a la luz de procesos actuales de reivindicaciones autóctonas diaguitas en el valle. 


\section{Referencias Citadas}

\section{Fuentes inéditas}

Archivo Nacional de Chile

Capitanía General, vol. 155, № 3, Autos seguidos por Bernabe de Riveros contra Joseph de Carvajal y Juan Roco, por estancia de Camasquil; 1633.

Capitanía General, vol. 578, s/ $\mathrm{N}^{\circ}$, Instrumentos del maestre de campo don Francisco de Cisternas; 1633.

Fondos Varios, vol. 342, Bandos de la Villa de San Francisco de la Selva; 1747-1798.

Fondos Varios, vol. 690, Sobre fundación de Copiapó; 1751.

Notarial Copiapó, vol. 1, Expediente por despojo de tierras a los indios en Copiapo entre el Protector General de Indios y el General Juan de Cisternas; 1677-1700.

Real Audiencia, vol. 50, s/ $\mathrm{N}^{\circ}$, El Protector de los Indios por el amparo y defenza de los del Valle de Copiapó contra el General Don Juan de Sisternas sobre el despojo de un Potrero en dicho valle y que de la Brea que hubiese sacado se les señale alguna parte; 1684.

Real Audiencia, vol. 1335, $\mathrm{N}^{\circ}$ 16, Cacicazgo del pueblo de Copiapó. Juicio contra Juan de Cisternas Carrillo, 1682.

Real Audiencia, vol. 1763, No 1, El Protector por la defensa de Don Juan Sacmay contra Francisco Taquia; 1677-1678.

Real Audiencia, vol. 2498, N 19, Don Bernabé de Riberos Figueroa Vezino de Coquimbo sobre que se apruebe y confirme la Posezion de sus tierras. Copiapo; 1635.

Fuentes publicadas, artículos científicos, capítulos y libros

Apeolaza, A. M.

[1756] 1995 Corregidor D. Antonio Martín Apeolaza. San Francisco de la Selva de Copiapó. 21/10/1755. En Relaciones geográficas del Reino de Chile, 1756, editado por Francisco de Solano, pp. 57-63. CSIC - Departamento de Historia Madrid - Universidad Internacional SEK Santiago de Chile, Santiago de Chile.

Astudillo Pizarro, F.

2018 "De la regionalidad política a la regionalidad económica: agua, minería y territorio en Atacama (siglos XVIII-XIX)". Boletín Americanista LXVIII(2-77): 81-103.

Bengoa, J.

2015 Historia rural de Chile central. Tomo I: La construcción del Valle Central de Chile, LOM ediciones, Santiago de Chile.

Berrios Drolett, F. y Lucero Villavicencio, J.

2011 "Antecedentes históricos sobre el uso del agua y sus conflictos en el valle de Copiapó a partir del siglo XVIII". Boletín del Museo Regional de Atacama 2:36-44.

Bibar, J. de

1966 [1558] Crónica y relación copiosa y verdadera de los reynos de Chile, editado por L. Irving A. Fondo Histórico y Bibliográfico José Toribio Medina, Santiago de Chile.

Bittmann, B.

1984 "Interrelaciones étnicas establecidas a lo largo de la costa del norte de Chile y sur de Perú en el contexto de la colonia: Los Camanchacas". Estudios Atacameños 7:327-334 Boccara, G.

1998 Guerre et Ethnogenèse Mapuche dans le Chili Colonial. L'Invention du soi. L'Harmattan, Clamecy.
Borde, J. y Góngora, M.

1956 Evolución de la propiedad rural en el Valle del Puangue. Universidad de Chile, Santiago de Chile.

Borlando Hipp, Í.

2011 Hacia una reevaluación de la ocupación incaica del litoral de la comuna de Caldera (III región de Atacama, Chile). Tesis para optar al grado de Arqueólogo, Universidad Internacional SEK, Santiago de Chile, Chile.

Borlando Hipp, Í.

2012 "Reflexiones en torno a la presencia incaica en el litoral de la comuna de Caldera (III región de Atacama, Chile)". Revista Werkén 14: 109-118.

Broll Carlin, J.

1988 "La lucha por el agua en el valle de Copiapó (17441810)". En Copiapó en el siglo XVIII, editado por Julio Broll Carlin y Jorge Pinto Rodríguez, pp. 127-146. Instituto de Estudios Humanísticos, Universidad de Valparaíso, Valparaíso.

Carmagnani, M.

1963 El Salariado minero en Chile colonial. Su desarrollo en una sociedad provincial: El Norte Chico 1690-1800. Universidad de Chile, Centro de Historia Colonial, Editorial Universitaria, Santiago de Chile.

Castillo Gómez, G.

1998 "Los períodos intermedio tardío y tardío: desde la cultura Copiapó al dominio Inca”. En Culturas Prehistóricas de Copiapó, editado por Hans Niemeyer, Miguel Cervellino y Gastón Castillo, pp. 163-282. Museo Regional de Atacama, Santiago de Chile.

Contreras Cruces, $\mathrm{H}$.

2016 "Migraciones locales y asentamiento indígena en las estancias españolas de Chile central, 1580-1650". Historia (Santiago) 49 (1): 87-110.

Córdova, E.

1968 "La encomienda y la desaparición de los indios en las Antillas Mayores". Caribbean Studies 8 (3):23-49.

Cortés Larravide, E.

2014 "Les femmes au sein de la sphère politique cacicale coloniale de la vallée de Copiapo, Royaume du Chili, XVIe siècle". Nuevo Mundo Mundos Nuevos. Disponible en línea: http://nuevomundo.revues.org/66589

Cortés Larravide, E.

2015 "La disparition des Indiens de Copiapó: dynamiques historiques et vulnérabilités humaines en milieu désertique au Chili (1744-1810)". L'Ordinaire des Amériques 218. Disponible en línea: http://orda.revues.org/1794

Cortés Larravide, E.

2016 “¿Existió un grupo llamado Copiapó en el valle homónimo? Reflexiones a partir de los testimonios coloniales". Revista Tiempo Histórico 12: 17-32.

Cortés Larravide, E.

2021 "Los primeros años de la encomienda de indios del valle de Copiapó: los aportes de la visita realizada en 1558 por Arias Pardo en nombre del licenciado Hernando de Santillán”. Fronteras de la Historia 26-2, en prensa.

Cortés Lutz, G.

2011 "El Fuerte Copiapó 1548; los orígenes urbanos de Copiapó, desde el siglo XVI hasta el presente". Boletín del Museo Regional de Atacama 2:14-22. 
Cortés Olivares, $\mathrm{H}$.

2003 "Evolución de la propiedad agraria en el Norte Chico (siglos XVI-XIX)". En Dinámicas de los sistemas agrarios en Chile árido: la región de Coquimbo, editado por Patrick Livenais y Ximena Aranda, pp. 33-64. Universidad de Chile - IRD - Universidad de La Serena, Santiago de Chile.

Cortés Olivares, $\mathrm{H}$.

2005 El origen, producción y comercio del pisco chileno, 15461931. Universum (Talca) 20 (2): 42-81. Disponible en línea: https://dx.doi.org/10.4067/S0718-23762005000200005

D’Esposito, F. y Jacobs, A. P.

2015 "Auge y ocaso de la primera sociedad minera de América. Santo Domingo 1503-1520”. Nuevo Mundo Mundos Nuevos. Disponible en línea: http://journals. openedition.org/nuevomundo/67723

Egaña, J.

1953 [1813] "Censo de 1813. Levantado por don Juan Egaña, de orden de la Junta de Gobierno formada por los señores Pérez, Infante y Eyzaguirre". Imprenta Chile - Archivo Nacional, Santiago de Chile.

Frézier, A.

1995 [1717] Voyage de la mer du Sud aux côtes du Chili et du Pérou. Utz, Dijon.

Garrido, F.

2007 El camélido sagrado y el hombre de los valles: Una aproximación a la Cultura Copiapó y sus relaciones a partir de la alfarería. Memoria para optar al grado de Arqueólogo, Universidad de Chile, Santiago de Chile, Chile.

Garrido, F. y González, S.

2020 "Adaptative Strategies during Times of Conflict and Transformation: Copiapó Valley under the Spanish Conquest in the Sixteenth Century". Etnohistory 67 (1): 127-148.

González Cortez, H. y Ruz Zagal, R.

2015 "Fe en el papel: la inscripción del dominio de las tierras de comunidad en el altiplano chileno". Diálogo Andino 46:143-152.

González Godoy, C.

2018 Síntesis de la prehistoria alfarera tardía del valle de Copiapó: desde las sociedades agrícolas locales (cultura Copiapó) a la presencia del Tawantinsuyu (1000 d. C. aprox.-1536 d. C.). Bajo la lupa, Colecciones Digitales.

Granados-Sánchez, D., Hernández-García, M. A., Vázquez-

Alarcón, A. y Ruíz-Puga, P.

2013 RCHSCFA 19 (1): 45-76.

Hämäläinen, P.

2012 L'empire comanche, Anacharsis, Toulouse.

Harambour R., A.

2015 "El ovejero y el bandido. Trayectorias, cruces y genocidio en dos relatos de viaje británicos en Tierra del Fuego (década de 1890)". Anales de Literatura Chilena 24: 163-182.

Hidalgo Lehuedé, J.

2004 [1971] "Población Protohistórica del Norte Chico". En Historia andina en Chile, Jorge Hidalgo Lehuedé, pp. 33-38. Editorial Universitaria, Santiago de Chile.

Iturriaga, R.

2006 Encuentros y desencuentros (Itinerario de la caminata franciscana). Ms.

Jara, Á.

1961 El salario de los indios y los sesmos del oro en la Tasa de Santillán. Centro de Investigaciones de Historia Americana - Universidad de Chile, Santiago de Chile.
Moyano Vasconcelos, R.

2009 "El adoratorio del cerro El Potro: arqueología de alta montaña en la cordillera de Copiapó, norte de Chile". Estudios Atacameños 38: 39-54.

Navia López, A.

2019 "Pueblos indígenas en Colombia: entre el petróleo y la supervivencia étnica. Estudio de caso del pueblo Cofán". Diálogo Andino 60: 127-139.

Niemeyer, $\mathrm{H}$.

1998 "El período temprano del horizonte agroalfarero en Copiapó". En Culturas Prehistóricas de Copiapó, editado por Hans Niemeyer, Miguel Cervellino y Gastón Castillo, pp. 61-114. Museo Regional de Atacama, Santiago de Chile.

Nugkuag Ikanán, E.

1994 "El desarrollo indígena autónomo en la Amazonía luego de 500 años". Caravelle 63: 195-208.

Oviedo y Valdés, G. F. de

1855 [1557] Historia General y Natural de las Indias, Islas y Tierra-Firme del Mar Océano. Tercera Parte - Tomo IV. Imprenta de la Real Academia de la Historia, Madrid.

Pinto Rodríguez, J.

1988 "Un mercado interior en Chile Colonial: El Corregimiento de Copiapó a fines del siglo XVIII". En Copiapó en el siglo XVIII, editado por Julio Broll C. y Jorge Pinto R., pp. 103-126. Instituto de Estudios Humanísticos, Universidad de Valparaíso, Valparaíso.

Ruiz Rodríguez, C.

2005 "La Conquista Española y Resistencia Indígena en el Norte Verde". En Los Pueblos originarios del Norte Verde. Identidad, Diversidad y Resistencia, Carlos Ruiz R., pp. 67-117. GORE Coquimbo, Santiago de Chile, Chile.

Salazar, G.

2003 Historia de la acumulación capitalista en Chile (Apuntes de clase). LOM Ediciones, Santiago de Chile.

Santillán, H. de

2004 [1558] "Relacion de las Visitas y tasas que el señor licenciado Fernando de Santillan oydor de su Magestad hizo de la cibdad de Santiago provincias de Chile de los repartimientos de yndios de sus terminos y de la cibdad de la Serena”. En Pueblos Originarios del Norte Florido de Chile editado por Hernán Cortés O., Patricio Cerda C. y Guillermo Cortés L., pp. 18-213. Fondart - Región de Coquimbo, La Serena.

Sayago, C. M.

1997 [1874] Historia de Copiapó. Editorial Francisco de Aguirre, Santiago de Chile.

Steiner Sampedro, C., Páramo Bonilla, C. y Pineda Camacho, R. compil.

2014 El paraíso del diablo. Roger Casement y el informe del Putumayo, un siglo después. Universidad de Los Andes - Universidad Nacional de Colombia, Bogotá.

Torres, A. de

1896 [1554] Declaración de Alonso de Torres. Cuarta información sacada de una probanza hecha por Lorenzo Maldonado, procurador de la ciudad de Santiago del Estero, contra el capitán Juan Núñez de Prado. En Colección de Documentos Inéditos para la historia de Chile - tomo X, pp. 192-194. Imprenta Elzeviriana, Santiago de Chile. 
Torres Sánchez, J.

1985 "Los conflictos de agua del valle de Copiapó en el siglo XVIII". Nueva Historia 4 (13-14): 3-105.

Valcárcel Rojas, R.

2019 "Revisitando el universo colonial. Arqueología de la interacción entre indígenas y europeos en Las Antillas". En Arqueología del contacto en Latinoamérica, editado por Lourdes S. Domínguez, Pedro P. Funari y Alexandre G. Navarro. Paco Editorial, Anhangabaú.

Valdivia, P. de

1898 [1549] Merced de encomienda a Francisco de Aguirre. En Colección de Documentos Inéditos para la Historia de Chile - tomo XV, pp. 220-222. Imprenta Elzeviriana, Santiago de Chile.
Valdivia, P. de

1978 [1549] "Al Emperador Carlos V. Santiago, 9 de julio de 1549”. En Cartas de Relación de la Conquista de Chile, pp. 81-83. Editorial Universitaria, Santiago de Chile.

Yáñez Fuenzalida, N. y Molina Otárola, R.

2011 Las aguas indígenas en Chile. LOM Ediciones-IWGIA, Santiago de Chile.

Zavala, J. M.

2000 Les Indiens mapuche du Chili. Dynamiques inter-ethniques et stratégiques de résistance, XVIII siècle. L'Harmattan-IHEAL, París.

Zuloaga Rada, M.

2012 La conquista negociada: guarangas, autoridades locales e imperio en Huaylas, Perú (1532-1610). IEPIFEA, Lima.

\section{Notas}

1 El conjunto de indígenas de Copiapó fue encomendado en una sola encomienda, que perduró hasta finales de la Colonia.

2 Se tienen evidencias que varias prácticas culturales y saberes locales relacionados con los habitantes autóctonos del valle perduraron durante los siglos XIX y XX, como por ejemplo en torno al ámbito minero y agrícola.

3 Dichos procesos, a pesar de haber sido llevados a cabo por iniciativa de comunidades autóctonas, se sustentan en un corpus legislativo que avala dichas iniciativas. Es interesante ver que ya a finales del siglo XIX hubo procesos en donde el Estado chileno también proveyó herramientas legales a ciertos grupos para que pudiesen legitimar ciertas prácticas comunitarias tradicionales, como es la propiedad colectiva de la tierra (González Cortez y Ruz Zagal 2015).

4 Existen testimonios que tras la gran campaña militar emprendida por el capitán Francisco de Aguirre en 1551, que apaciguó todo el Norte Chico, hubo intentos de sublevaciones, en especial tras la captura y ejecución del gobernador del reino Pedro de Valdivia (Torres 1896: 193 [1554]).

5 No fue así para los habitantes costeros camanchacas/ changos que a mediados del siglo XVI formaban parte de la encomienda de indios de Copiapó. En efecto, al disponer de medios de movilización eficaces, ellos lograron romper progresivamente los lazos que los ligaban a sus encomenderos sucesivos.

6 En la zona costera, comúnmente asociada al universo camanchaca/chango, dicha continuidad también ha sido demostrada por diferentes estudios arqueológicos e históricos, investigaciones que igualmente han demostrado una diferencia entre dichas poblaciones y aquellas del valle (Borlando 2011).
7 La zona de Nantoco, donde hubo un pueblo de indios y una iglesia, fue totalmente destruida en 1655 por un alud debido a fuertes precipitaciones tras un largo período de sequía (Sayago 1997 [1874]).

8 Los diferentes datos de los que disponemos dejan en evidencia la existencia de varios pueblos prehispánicos: Caldera, Copiapó, Hornitos, La Puerta, Painegue, Viña del Cerro y Choliguín (Borlando 2011; Castillo 1998; Moyano 2009). Paralelamente las fuentes confirman la existencia de Choliguín durante el primer contacto hispano-indígena en 1537 (Oviedo 1885:268 [1557]) y probablemente Copiapó (Valdivia 1978:81 [1549]; Bibar 1966 [1558]). En cuanto a La Puerta, cercano a El Fuerte, suponemos que la decisión de Bohón en edificar su base en este lugar se sustentó en la existencia de algún centro administrativo inka, tal como lo decidió para la erección de La Serena, además de haber existido no lejos de allí un poblado indígena (Archivo Nacional de Chile [ANCh], Real Audiencia [RA], vol. 50, s/ $\mathrm{N}^{\circ}$ ). Además, fuentes de los siglos XVI y XVII indican igualmente ciertos pueblos que desaparecieron con rapidez (ANCh, RA, vol. 50, s/ $\mathrm{N}^{\circ}$ ). Ignoramos si los pueblos mencionados durante la visita de 1558 por Santillán corresponden a sitios que fueron ocupados antes de la llegada de los españoles o se trata de pueblos instalados a modo de reducciones.

9 Dicho capitán había contraído matrimonio con doña Inés de Aguirre Matienzo, hija de Hernando de Aguirre (y nieta del gobernador Francisco de Aguirre), y de doña Agustina Matienzo, hija de don Juan de Matienzo.

10 Hasta 1652 extraían igualmente brea en Chamonate. Sin embargo, ese año estas tierras fueron concedidas en merced a Juan de Cisternas Carrillo Escobar. Estos campos de brea desaparecieron igualmente tras las inundaciones de 1655. 